- $\quad$ One of the first attempts made in Europe to convert municipal sludge to biodiesel.

- $\quad$ First attempt to optimise the yield of lipids extracted with pre-treatments.

- $\quad$ First attempt to compare four sludge of different characteristics from the WWTP.

- $\quad$ Primary sludge has a conversion to FAME of $19 \%$ in dried sludge basis.

- $\quad$ Pre-treatments do not affect essentially conversion and composition of FAME. 


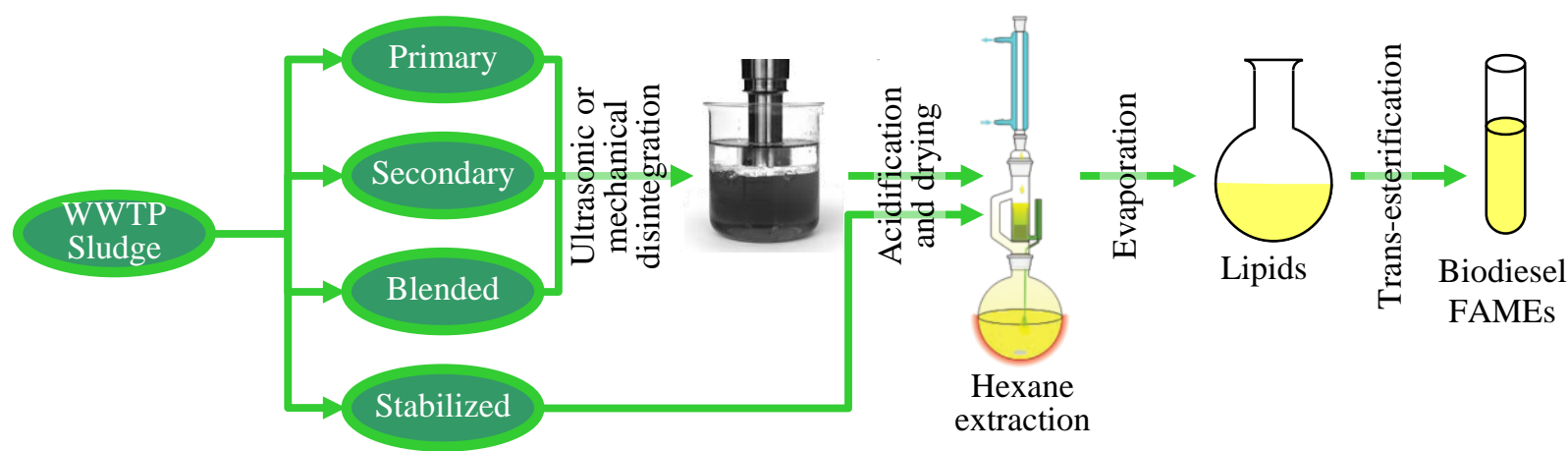




\section{Effects of pre-treatments on the lipid extraction and biodiesel production from municipal WWTP sludge}

3 Magdalena Olkiewicz a ${ }^{\text {, }}$ Agustí Fortuny ${ }^{\text {b }}$, Frank Stüber ${ }^{\mathrm{a}}$, Azael Fabregat ${ }^{\mathrm{a}}$, Josep Font ${ }^{\mathrm{a}}$, Christophe Bengoa ${ }^{\mathrm{a}, *}$ (1)

a Departament d'Enginyeria Química, Universitat Rovira i Virgili, Av. Països Catalans 26, 43007 Tarragona, Spain.

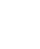

${ }^{\mathrm{b}}$ Departament d'Enginyeria Química, Universitat Politécnica de Catalunya, Av. Víctor Balaguer S/N, 08800 Vilanova i la Geltrú, Spain.

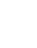

* Corresponding author. Tel.: +34-977-558619; fax: +34-977-559667.

E-mail address: christophe.bengoa@urv.cat

Abstract

Biodiesel production is currently limited due to high raw material costs. The potential of using sludge from municipal wastewater treatment plants as an alternative lipid feedstock was investigated. Four different types of sludge (primary, secondary, blended and stabilised) were tested in lipid extraction by Soxhlet using hexane, and biodiesel production by acid catalysis. To improve the extraction efficiency, the influence of pre-treatment methods (ultrasonic and mechanical disintegration) and duration of these treatments were investigated. Finally, the effect of sludge acidification with concentrated $\mathrm{HCl}$ was also evaluated. The pre-treatment methods did not increase significantly the amount of extracted lipid as well as biodiesel yield. Previous sludge acidification showed lower yield of lipids from primary, secondary and blended sludge. However, the amount of saponifiable lipids was higher, giving the overall 
biodiesel yield almost unchanged. Among the four sludges tested, primary sludge achieved the greatest lipid and biodiesel yields, $27 \%$ and $19 \%$ respectively, on the basis of dry sludge. The highest biodiesel yields obtained from blended, secondary and stabilised sludge amounted to $15 \%, 4 \%$ and $2 \%$ respectively, on the basis of dry sludge. No significant influence of the pretreatments and acidification on the fatty acid composition was found. At least 8 fatty acids were determined, with a predominance of palmitic (C16:0), stearic (C18:0) and oleic acid (C18:1). The comparison of sludge fatty acids profile with common biodiesel feedstocks showed suitability of WWTP sludge for production of biodiesel.

\section{Key-words}

WWTP municipal sludge; biodiesel; lipid extraction; sludge acidification; ultrasonication; mechanical disintegration.

\section{INTRODUCTION}

Biodiesel is one of the most promising renewable fuels as it is biodegradable, less toxic than fossil diesel, compatible with current commercial diesel engine and refuelling technology, and it has low emission profile. Additionally, it has excellent lubricating properties and it could provide energy density similar to diesel [1-4]. Biodiesel is generally produced by transesterification of vegetable oils or animal fats, yielding fatty acids methyl esters (FAMEs) from the lipid fraction. The production of biodiesel in the EU increased from 3.6 (2005) to 10.7 billion litres in 2010 [5]. However, nowadays the competitive potential of biodiesel is limited due to high cost of common lipid feedstocks (soybean, canola, rapeseed, sunflower, palm, and coconut oils), which constitutes $70-85 \%$ of the overall biodiesel production cost, strongly influencing the final price of this biofuel $[2,3,6,7]$. In fact, the production of biodiesel decreased by $10 \%$ in 2011 as compared to 2010 [5]. In addition, lack of agricultural lands for growing biodiesel feedstocks limits biodiesel expansion and has contributed to the 
increase of food prices over the past few years, raising the concerns of food shortage versus fuel crisis [3]. Thus, there is an urgent need to find an alternative, cheaper feedstock, nonedible, readily available and in large quantities.

In contrast, municipal sewage sludge that is gaining more attention nowadays in biodiesel production can meet the requirements of lipid feedstock $[3,4,8]$. Sewage sludge is a waste, formed during treatment of wastewater in wastewater treatment plants (WWTPs) that needs specific treatment before disposal and represents a major cost in WWTP operation. In addition, WWTPs annually produce higher amounts of sludge due to the expansion of urbanised and industrialised areas. Each year, higher quantities of sludge are produced and the number is estimated to increase from 10 million tons (2005) to 13 million tons in 2020 in the whole of EU [9]. Additionally, dry sludge could comprise up to $30 \mathrm{wt} \%$ of lipids $[10,11,12]$, which could be converted into FAMEs. Recent studies have indicated that lipid contained in sewage sludge could be potential feedstock for biodiesel $[1,6,7,11,13]$. Nevertheless, production of biodiesel from sludge poses great challenges for fast commercialisation. The optimisation of lipid extraction is a major challenge that may affect the economy of the process [7].

It has been demonstrated that ultrasonic pre-treatment $[14,15]$ and acid hydrolysis [16] are able to increase the lipid extraction yield from biologic samples but their utilisation to improve lipid extraction from sludge has not been reported. These pre-treatments are able to release the lipids from other macromolecules which are not available to solvent in bonded form. Therefore, the utilisation of the sludge pre-treatments could also improve the efficiency of extraction. The most common methods of sludge pre-treatment are ultrasonication and mechanical disintegration, commonly used to enhance biogas production $[17,18,19,20]$. Ultrasonic energy is able to disintegrate sludge flocs and disrupt large organic particles, breaking down bacterial cell wall and releasing intracellular substances and extracellular polymeric substances into aqueous phase $[14,15,17,20]$. Mechanical disintegration is used to 
reduce size of the sludge particles, disintegrate cells and release organic components into sludge $[18,19]$. On the other hand, acid hydrolysis of sludge is another pre-treatment method used to increase the solubility of the organic matter contained within sludge and thus to reduce the amount of sludge and improve its dewaterability [21]. As sewage sludge is a processed sample, in which lipid can be bonded to proteins, carbohydrates and/or minerals, the proposed pre-treatment methods could facilitate the extraction of lipids by sludge disintegration.

The purpose of this study was to investigate the influence of sludge type (primary, secondary, blended and stabilised) and sludge pre-treatments (ultrasonic and mechanical), combined with or without sludge acidification, on the yield of lipid extracted as well as biodiesel (FAMEs) produced. Finally, the composition of FAMEs was determined and compared with common biodiesel feedstocks.

\section{MATERIALS AND METHODS}

\subsection{Chemicals}

Lipid extraction experiments were conducted using hexane of laboratory reagent grade (ref: 208752) and magnesium sulphate monohydrate (ref: 434183) purchased from Sigma-Aldrich. Fuming hydrochloric acid (ref: 84418) used for sludge acidification was purchased from Fluka. Transesterification experiments were carried out using hexane (ref: 34859), anhydrous methanol (ref: 322415) and sulphuric acid (ref: 33974) from Sigma-Aldrich at the highest purity available. Sodium chloride (ref: 71379), sodium bicarbonate (ref: S6297) and anhydrous sodium sulphate (ref: 239313) were provided by Sigma-Aldrich. Standard used for identification and quantification of fatty acid methyl ester (FAMEs) was supplied by Supelco (37 component FAMEs mix, ref: 47885-U). Analytical standards of free fatty acids (FFA) were provided by Sigma-Aldrich (C12 ref: L556, C14 ref: 70082, C15 ref: 96125, C16 ref: P0500, C16:1 ref: P9417, C18 ref: S4751, C18:1 ref: O1008, and C18:2 ref: L1376. High 
104 Performance Liquid Chromatography (HPLC) grade toluene (ref: 650579) used for

105 preparation of FFAs solution was also provided by Sigma-Aldrich.

\subsection{Sludge collection, handling and characterisation}

108 Primary, secondary, blended and stabilised sludge were collected from the municipal WWTP

109 in Reus (Tarragona, Spain) with a capacity to process near $25,000 \mathrm{~m}^{3}$ of wastewater per day.

110 Primary sludge was collected after partial gravity thickening. Secondary sludge, produced by

111 an activated sludge process, was collected after partial thickening by flotation. Blended sludge

112 was collected after the combination of primary and secondary at a ratio of $65: 35$, v/v in the

113 feed of the anaerobic reactor. Stabilised sludge, produced by an anaerobic digestion was

114 sampled after belt filter press dewatering. Sludge samples were taken every 2-3 weeks and the

115 sampling was done four times. The samples were immediately delivered to the laboratory and

116 stored at $4^{\circ} \mathrm{C}$ prior to use (maximum storage time 7 days).

117 Each sample of received sludge was characterised in order to determine total solids (TS) and

118 volatile solids (VS) content, both according to standard method 2540G [22]. Chemical oxygen

119 demand (COD) was measured in a UV-spectrophotometer (DINKO UV-VIS 800

120 spectrophotometer) according to standard method 5220D [22]. The Sludge characteristics are

121 given in Table 1. As the sludge composition varies during the wastewater treatment and

122 depends on the specific treatment applied, therefore the stabilized sludge gave the largest

123 content of TS and VS due to the water elimination by filter press system, and the primary

124 sludge gave higher quantity of TS, VS and COD than blended and secondary.

\subsection{Pre-treatment of sludge samples}

127 Before the extraction, primary, secondary and blended sludge were pre-treated using

128 ultrasonic and mechanical disintegration methods. Due to its solid appearance, anaerobically

129 stabilized sludge was used as received without previous disintegration. 
130 The ultrasonic disintegration experiments were carried out using the procedure previously

131 described elsewhere [23]. The mechanical disintegration experiments were carried out using a

132 mechanical homogenizer (Taurus, Turbo-rotation system) at $600 \mathrm{~W}$ of the input of energy at

133 room temperature. $200 \mathrm{ml}$ of sludge was used for each test of each disintegration method. In

134 order to optimise the disintegration time, the blended sludge was disintegrated by both

135 methods for 5, 10, 15 and 20 min.

136 After sludge disintegration, one part of disintegrated samples and one part of untreated

137 samples were acidified till $\mathrm{pH} 2$ at ambient temperature. That $\mathrm{pH}$ was attained by the addition

138 of approximately $0.3 \mathrm{~mL}$ of concentrated $\mathrm{HCl}$ to the sample of $20 \mathrm{~mL}$ of sludge, which

139 afterwards was used directly in the lipid extraction experiment.

140 To evaluate the effect of sludge disintegration, the blended sludge after each pre-treatment

141 was characterized by Scanning Electron Microscopy (SEM (Jeol JSM-6400)) to observe the

142 appearance of the floc size. For this purpose, a drop of each sludge sample was deposited on

143 the support, dried at room temperature and then coated under vacuum with a gold layer before 144 examination.

\subsection{Extraction of lipids}

147 In order to compare the influence of pre-treatment methods, the extraction experiments were

148 carried out using untreated, ultrasonically disintegrated and mechanically disintegrated

149 primary, blended and secondary sludge with and without acidification. The stabilized sludge

150 was subjected to lipid extraction with and without sludge acidification. According to standard

151 procedure the lipid was extracted from acidified untreated sludge 5520E [22], and the

152 utilisation of acidified untreated sludge in the extraction was used as a reference method.

153 Before the extraction, the samples were dried by adding magnesium sulphate monohydrate

154 according to standard method 5520E [22]. The mixture was stored in a desiccator at room

155 temperature overnight. The lipid extraction procedure was carried out in a Soxhlet apparatus 
using hexane as a solvent, according to standard method 5520E [22]. After the lipid

extraction, the hexane was removed from the flask using a rotary evaporator. The flask,

containing the lipids, was stored in a desiccator overnight and weighed the next day. The yield

of extracted material was determined gravimetrically and expressed as weight of lipid hexane, and kept frozen at $-20^{\circ} \mathrm{C}$ until further analysis.

\subsection{Lipid and biodiesel analysis}

164

The amount of FFA in extracted lipid was determined using an Agilent gas chromatograph 6890GC with a flame-ionization detector (GC-FID). Separation was achieved in an Agilent HP-INNOWax column (19091N-133) using helium as a carrier gas. The injection volume of a sample was $1.5 \mathrm{~mL}$ with a split ratio $100: 1$. The oven temperature programme began at $60^{\circ} \mathrm{C}$, holding for $2 \mathrm{~min}$ and increased by $10^{\circ} \mathrm{C} / \mathrm{min}$ to $200^{\circ} \mathrm{C}$, and then increased by $10^{\circ} \mathrm{C} / \mathrm{min}$ to $240{ }^{\circ} \mathrm{C}$, holding for $12 \mathrm{~min}$. The detector and injector temperature were set at $250^{\circ} \mathrm{C}$ for the duration of the analysis.

The lipids were converted into FAMEs (biodiesel) through acid catalysis transesterification/esterification using a modified version of Christi's method [10] and the FAMEs were analysed by GC-FID and GC-MS as described elsewhere [10]. The results of GC-FID were used to estimate the amount of saponifiable (trans/esterifiable) material in the lipid fraction and hence the maximum mass of biodiesel (FAMEs) that could yield. The compounds which could not be identified by GC-FID are presented as others. The other compounds identified by GC-MS are described in Section 3.1.3.

\section{RESULTS AND DISCUSSION}

\subsection{Influence of sludge type}

\subsubsection{Lipid extraction yield}


The lipid yield extracted from the four type of sludge tested is illustrated in Table 2. The

183 values represent the average of at least three different samples collected in WWTP during several months. Irrespective of the sludge pre-treatment and acidification, the primary sludge achieved the greatest lipid yield (27\%) followed by blended (21\%), secondary (9\%) and stabilised (9\%). This fact was predictable because the composition of primary sludge consists essentially of organic matter originated from raw wastewater, which is a combination of floating grease and solids (the highest lipid fraction). On the other hand, secondary sludge is composed mainly of microbial cells and suspended solids produced during the aerobic biological treatment of the primary treated wastewater; the lipid fraction comes mainly from extracellular polymeric substances and cell membrane of microorganisms. As blended sludge is a mixture of primary and secondary, with a higher fraction of the first one, the result is slightly lower than of the primary. Finally, in the case of stabilised sludge, it comes from anaerobic digestion process of blended sludge, during which the organic matter is degraded into intermediary products then converted into methane. However, stabilised sludge gave the same yield of lipid as secondary sludge. This is due to possible co-extraction of non-lipid fraction which contributes to the increase in gravimetric yield (see Section 3.1.2.).

\subsubsection{Biodiesel (FAME) yield}

200 Total lipid content extracted from sludge is not the real one that could be converted to

201 FAMEs-biodiesel. Lipid fraction extracted from sludge using non-polar solvent can consist 202 not only of acyglycerols, free fatty acids and some waxes (saponifiable lipids), but also of hydrocarbons, pigments, trepans, linear alkyl benzenes, polycyclic aromatic hydrocarbons, sterols and other waxes [8, 24]. Only acyglycerols and free fatty acids that represent the saponifiable part of lipids are suitable for biodiesel (transesterifiable/esterifiable to FAMEs). Hydrocarbons, other non-polar substances (non-lipids) that could be co-extracted with hexane, and also part of lipids like some waxes and sterols are considered as non-saponifiable lipids. 
Non-saponifiable lipids are not convertible into biodiesel and represent lipid contaminants.

209 Therefore, the yields of saponifiable lipids and overall biodiesel yields produced from the four 210 sludge types were analysed and the results are presented in Table 3. Irrespectively of sludge 211 pre-treatments and acidification the primary sludge achieved the greatest saponifiable yield $212(69 \%)$ followed by blended (56\%), secondary (41\%) and stabilised sludge (14\%). Thus, the 213 overall biodiesel yields were $18 \%, 11 \%, 4 \%$ and $1 \%$ for primary, secondary, blended and 214 stabilized untreated sludge, respectively. Comparison between stabilised and secondary sludge 215 indicates that although the amount of lipids extracted from both was the same (Table 2), the 216 secondary gave a higher overall biodiesel yield owing to a much larger amount of saponifiable 217 matter in the lipid extracted. This shows that an extraction from stabilised sludge produce 218 lipids heavily contaminated with non-saponifiable material, causing a lower productivity of 219 biodiesel. Among the sludge tested, primary sludge has the higher quantity of extractable 220 lipids and additionally it has also the best quality of lipids that are able to form FAMEs. For 221 these reasons, primary sludge can be considered a better feedstock for biodiesel production 222 than other type of sludge generated in WWTPs. On the other hand, the elimination of lipids 223 from primary sludge can significantly reduce the amount of lipids in blended sludge which is 224 the feed of the anaerobic digester. It is known that significant amount of lipids can negatively 225 affect anaerobic digestion process [25]. Therefore, the extraction of lipids from primary 226 sludge to produce biodiesel will additionally improve the performance of the anaerobic 227 digester and the production of biogas.

\subsubsection{Fatty acids composition}

230 Fatty acid compositions of biodiesel produced from sludge are presented in Tables 4. All types 231 of sludge have a significant amount of palmitic acid (C16:0), stearic acid (C18:0), oleic acid 232 (C18:1) and linoleic acid (C18:2). These results are confirmed by the comparison with the 
composition of human faecal fatty acids, dominated by C16:0, C18:0 and C18:1 and by

234 kitchen wastes, dominated by C16:0, C18:0, C18:1 and C18:2 [24].

235 The significant difference was found in secondary sludge as compared to primary and

236 blended. Secondary sludge which comes from biological process in the presence of

237 microorganisms contains high amounts of $\mathrm{C} 16: 1(11.6 \%)$ but not of $\mathrm{C} 15: 0(0.3 \%)$ which both 238 are considered to be bacterial [24]. In contrast, the amount of C16:0 is lower $(21.2 \%)$ than the 239 amount in primary (39.0\%) and blended (40.7\%) sludge. Additionally, the amount of "others" 240 is the highest (16.9\%). On the other hand, primary sludge had lower amount of "others", 241 identified by GC-MS, which mainly consist of methyl 10-hydroxyhexadecanoate, methyl 13242 methyltetradecanoate, methyl 12-methyl-tetradecanoate, methyl 15-methylhexadecanoate, 243 methyl-14methylhexadecanoate benzenoacetic acid methyl ester and benzenopropanoic acid 244 methyl ester; or other substances like 1-decene, 1-tetradecene and cyclotetradecane. The 245 composition of blended sludge is very similar to primary sludge, the highest difference was 246 found in the amount of oleic acid (C18:1) and "others". Finally, in the case of stabilised 247 sludge, the first acid detected was palmitic acid (C16:0).

\subsubsection{Comparison of sludge oil with other biodiesel feedstock}

As primary sludge achieved the best yield of lipid and the highest overall yield of biodiesel,

251 the fatty acid composition of primary sludge was compared to common biodiesel feedstocks 252 as shown in Figure $1[26,27]$. It can be observed that the most of fatty acids found in the 253 sludge are the same as compared to other feedstocks; palmitic acid (C16:0), stearic acid 254 (C18:0), oleic acid (C18:1), and linoleic acid (C18:2). The important difference is observed in the lower amount of $\mathrm{C} 18: 2$ and the absence of $\mathrm{C} 18: 3$ in sludge fatty acids profile as compared to the profiles of soybean and rapeseed. This fact is an advantage because these polyunsaturated fatty acids can undergo reactions such as auto-oxidation due to the bis-allylic 258 position of the carbon double bonds, provoking a destabilisation of biodiesel [28, 29]. The 
polyunsaturated fatty acids in the biodiesel from primary sludge constitute only $7 \%$, as

260 compared to $61 \%, 31 \%$ and $30 \%$ in the biodiesel from soybean, rapeseed and waste cooking

261 oil, respectively. This fact is an interesting benefit because feedstock rich in saturated or

262 monounsaturated fatty acids gives biodiesel higher oxidation stability [26, 29].

263 On the contrary, the level of saturated fatty acids found in the sludge (65\%) is much higher

264 than the saturation level of other biodiesel feedstocks, and it may present a problem for the

265 cold flow properties of biodiesel. The significant amounts of saturated fatty compounds,

266 increasing the temperature at which a liquid biodiesel, when cooled, becomes cloudy due to

267 formation of crystals and solidification of saturates. However, the cold flow problem can be

268 overcome by using branched chain alcohols instead of methanol in the reaction of

269 transesterification $[26,28]$ and/or by the presence of branched-chain and hydroxy fatty acid

270 monoalkyl esters [10]. Actually, branched-chain and hydroxy fatty acid, identified by GC-

271 MS, exist in sludge lipids and were included as "others" in Tables 4 (see Section 3.1.3.).

272 Thereby, the cold flow properties of biodiesel produced from primary sludge could be even

273 better because of the presence of other fatty acid methyl ester.

\subsection{Influence of the acidification}

Table 2 also shows the results of lipid yields from the four sludge types with and without

277 acidification. Irrespective of sludge pre-treatments, the acidification gave slightly lower yield

278 of lipid extracted from primary, secondary and blended sludge as compared to the sludge

279 without acidification. Although in this study, the sludge was acidified at ambient temperature,

280 just by adjusting $\mathrm{pH}$ until 2, the sludge hydrolysis accrued giving more dissolved DQO after

281 sludge acidification (increase from $3 \mathrm{~g} / \mathrm{L}$ to $3.8 \mathrm{~g} / \mathrm{l}$, blended sludge). After sludge acidification

282 the hydrolysis could release lipids from proteins and/or carbohydrates giving more esterifiable

283 (saponifiable) lipids (Table 3), and leaving the polar compounds unextracted. Furthermore,

284 the phospholipids, triglycerides, wax esters and sterol esters found in the sludge may have 
been also hydrolyzed into FFAs [30] leaving the polar fraction (glycerol, alcohol and

286 phosphate group) unextracted, resulting in a decrease in gravimetric yield. On the other hand,

287 the lipid yield of stabilised sludge increased after acidification. It could be due to release the

288 lipid bonded to the mineralised matter, which contains traces amounts of macromolecular

289 compounds, causing a slight higher yield.

290 The results of FFA analysis confirmed that sludge acidification increases the amount of FFA

291 in the lipid extracted from all sludge types. The lipid extracted from untreated primary,

292 blended, secondary and stabilised sludge contained $48.2 \%, 42.8 \%, 23.4 \%$ and $8.9 \%$ of FFA

293 (on the basis of lipid), respectively. After sludge acidification the amount of FFA in extracted

294 lipids increased to $60.3 \%, 50.1 \%, 27.2 \%$ and $9.9 \%$ for primary, blended, secondary and

295 stabilised sludge respectively. The larger increase of FFA in primary and blended sludge as

296 compared to secondary and stabilised is related to the conversion of insoluble soaps, present

297 in primary sludge, into FFAs upon exposure to an acidic environment [10]. As a result of

298 higher amount of FFAs in the lipid extracted after sludge acidification, the amount of

299 saponifiable lipids also increased, and the higher increase is observed for primary and blended

300 sludge (Table 3). These results show that an extraction from acidified sludge produces lipids

301 less contaminated with non-saponifiable material. However, the overall biodiesel yield

302 increased only slightly in the case of primary, blended and stabilised sludge. Secondary sludge

303 gave lower overall biodiesel yield after sludge acidification owing to a lower amount of lipid

304 extracted.

305 As shown in Tables 4a, 4b and 4d, irrespectively of sludge pre-treatments, the effect of sludge

306 acidification of primary, secondary and stabilized sludge in general shows increase in the

307 amount of palmitic acid (C16:0) and decrease in the amount of oleic acid (C18:1). In the case

308 of blended sludge the opposite situation occurs. However, the difference is not essential

309 (Table 4c). 


\subsection{Influence of the pre-treatments}

\section{2 3.3.1. Optimisation of pre-treatment time on the lipid extraction yield}

In order to optimise the duration of pre-treatments, untreated blended sludge was disintegrated

314 by ultrasonic and mechanical method for 5, 10, 15 and 20 minutes. For both pre-treatment

315 methods, the maximum lipid yield was achieved after 10 minutes of sludge pre-treatments,

316 giving $23 \%$ and $22 \%$ of lipid (based on dry sludge) for ultrasonic and mechanical pre-

317 treatment, respectively. A further increase in the pre-treatment time until 15 and 20 minutes

318 indicates a decrease in the extraction efficiency to a value close to untreated sample, $21 \%$

319 (based on dry sludge). After the first 10 minutes of the pre-treatment, the recovery of lipid was

320 enhanced by the disruption or disintegration of flocs and/or the lysis of the bacterial cells, thus

321 improving the availability of the organic matter to the solvent. However, maintaining the

322 sludge disintegration more than 10 min could increase the size of particle gradually, due to re-

323 flocculation of the particles by the appearance of new linkages of the organic matter from

324 intracellular and extracellular substances which initially were released [17]. According to the

325 results, 10 min of pre-treatment for both, ultrasonic and mechanical disintegration was chosen 326 as the pre-treatment duration for this study.

\subsubsection{Evaluation of the pre-treatments}

329 The lipid, saponifiable and biodiesel yields obtained from primary, secondary and blended

330 sludges by difrent pre-treatment methods are presented in Table 2 and 4 . Surprisingly, the 331 sludge pre-treatments were not able to enhance substantially neither the yield of lipids nor 332 saponifiable and biodiesel yields, irrespective of sludge acidification. The ultrasonic and 333 mechanical pre-treatment methods were chosen because of their capacity to disintegrate 334 sludge, what may lead to better homogenization of the sample and better penetration of the 335 solvent into the sample [15]. Furthermore, the methods are able to disintegrate the sludge

336 flocs, break down bacterial cell wall and release the lipid present in extracellular polymeric 
substances of bacterial sludge flocs [17]. As secondary sludge comes from aerobic biological

338 process, it is composed mainly of microbial cells and suspended solids, the slight improvement in the extraction end transesterification yields after sludge pre-treatment is

340 observed in some cases of secondary and blended sludge. However, the differences are not

341 significant (Table 2 and 4). Comparing both pre-treatment methods, in general ultrasonic

342 treatment gave better results of lipid, saponifiable and biodiesel yields than mechanical.

343 Nevertheless, again the differences are not significant.

344 In order to observe the effect of sludge disintegration the photos of the microscopic 345 appearance of the blended sludge floc were taken and are illustrated in Figure 2 . There is only

346 a slight difference on the microscopic appearance of the sludge floc between acidified (Figure 347 2b) and untreated sludge (Figure 2a). The acidification had almost no effects on the floc size; 348 although the floc texture seems to be a little bit looser, the structure and the size of floc is 349 basically the same as the original sludge. Bigger differences can be observed between 350 untreated and treated sludge. As it can be seen in Figure 2a, the untreated sludge has big and 351 incoherent floc structure, while after pre-treatments, Figure $2 \mathrm{c}$ and $2 \mathrm{~d}$, the appearance of floc 352 structure is compacted and smaller in size due to the disintegration process. The same 353 differences were reported elsewhere [31]. Comparing both pre-treatments, in the case of 354 ultrasonication the floc texture is more separated than the structure of mechanically pre355 treated sludge, due to a better disintegration of sludge floc and decrease in particle size by 356 ultrasonic treatment.

357 As shown in Tables 4, there is no significant influence of the pre-treatments on the fatty acid profiles of primary (Table 4a), secondary (Table 4b) and blended (Table 4c) sludge.

\subsection{Statistical evaluation}

361 In order to identify statistically significant differences in the results of lipid, saponifiable and

362 biodiesel yields between different pre-treatment methods and sludge acidification a two-way 
analysis of variance (ANOVA) at a 95\% confidence level $(\mathrm{p}<0.05)$ was performed on primary, blended, and secondary sludge. The results of the test revealed no significant interaction effect ( $\mathrm{p}>>>0.05)$ of the two factors investigated on the lipid, saponifiable and biodiesel yields for primary, blended and secondary sludge. Furthermore, the test for the three types of sludge (primary, blended and secondary) indicated no significant differences ( $\mathrm{p} \gg>$ $0.05)$ on the lipid, saponifiable and biodiesel yields between three pre-treatments tested (untreated, ultrasonic, mechanical). However, the results of the test indicated significant difference on the lipid yield between acidified and non-acidified secondary sludge $(\mathrm{p}=$ 0.0039). Primary $(\mathrm{p}=0.1164)$ and blended $(\mathrm{p}=0.1595)$ sludge did not show the significant influence of acidification on the lipid yield. On the contrary, the saponifiable yield was found to be significantly affected by the acidification of primary $(\mathrm{p}=0.0397)$ and blended $(\mathrm{p}=$ 0.0049) sludge while secondary sludge did not show significant differences $(p=0.4451)$. Finally, the results of the test indicated significant difference on the biodiesel yield between acidified and not acidified secondary $(\mathrm{p}=0.0066)$ and blended $(\mathrm{p}=0.0315)$ sludge while primary sludge did not show significant differences $(p=0.1443)$.

On the other hand, to identify statistically significant differences between the data with and without acidification obtained from stabilised sludge, a $t$-test at the 0.05 significance level was performed. The results of the test showed that there is no significant differences between acidified and non-acidified sludge on the lipid $(p=0.0992)$, saponifiable $(p=0.3333)$ and biodiesel $(\mathrm{p}=0.0917)$ yields.

\subsection{Comparison with other processes of production of biofuels}

In the best scenario of this study, the production of biodiesel from sewage sludge can reach a maximum of $19 \%$ based on dry matter. The best alternatives to compete with biodiesel production to make fuels from the volatile matter of dry sludge are direct combustion, gasification, pyrolysis and liquefaction. These processes are able to produce the thermal 
decomposition of the organic matter and to transform this organic matter into bio-fuels [32].

390 Among this processes, liquefaction is gaining more attention due to better condition of low temperature and pressure [33].

392 The treatment of dried sewage sludge by liquefaction in water at $340^{\circ} \mathrm{C}$, catalyzed by sodium 393 carbonate was able to produce heavy oils with a conversion of $42 \%$ based on dry matter [34].

394 Moreover, the same results were obtained in a continuous pilot plant treating 5 tons/day of 395 dewatered sludge [35]. Recently, sewage sludge was processed by deoxy-liquefaction in 396 supercritical ethanol producing up to $55 \%$ of bio-oil at $400^{\circ} \mathrm{C}$ in methanol [32] and until $46 \%$ of conversion to bio-oil at $380^{\circ} \mathrm{C}$ and 7.5 $\mathrm{MPa}$ in acetone [33]. Since bio-oil and biodiesel are biofuels with different characteristics, only the heating value of both of them can be compared to have an idea of the energy that can be recovered. The heating value of bio-oils was in the range of 35 to $39 \mathrm{MJ} / \mathrm{kg}$ [32, 33], comparable to $39.5 \mathrm{MJ} / \mathrm{kg}$ from biodiesel [8]. The composition of the bio-oils depends on the solvent used during process, but more than a

402 hundred of substances are usually identified. For instance, when acetone is used as solvent in hydrothermal liquefaction, the bio-oils are essentially composed by ketones. On the other side, when methanol or ethanol is used, some esters are obtained [33], until $25 \%$ of the bio-oil, that are also found in biodiesel. Finally, regarding to biodiesel production cost from sludge, different studies estimated cost of $0.83-0.85 \$ / L[6,11]$, although the yields of conversion to biodiesel were 7 and $10 \%$ based on dry sludge, lower than the $19 \%$ obtained in this study.

\section{CONCLUSIONS}

The pre-treatment methods tested in this study are not able to increase significantly the

411 amount of extracted lipid as well as biodiesel yield. Thus, the pre-treatments are not suitable

412 for biodiesel production from municipal sewage sludge. The sludge acidification showed

413 lower extraction efficiency as compared to non-acidified sludge, while the amount of 414 saponifiable lipid was higher, and giving the overall biodiesel yield almost unchanged. 
415 Gas chromatography analysis of the FAMEs indicated a similarity between the fatty acid

416 compositions of the four sludge evaluated. All types of sludge have a significant amount of

417 palmitic acid (C16:0), stearic acid (C18:0) and oleic acid (C18:1), which are essential for the

418 production of biodiesel.

419 The results have shown that all types of municipal sludge produced during wastewater

420 treatment are a potential source of suitable lipid for the production of biodiesel. Among the

421 four sludge tested, the primary sludge achieved the greatest lipid (27\% based on dry sludge)

422 and biodiesel (19\% based on dry sludge) yield. Thus, primary sludge is the most beneficial

423 lipid feedstock for biodiesel production. Furthermore, it is possible to take advantage of the

424 excess sludge, reusing it as a source of lipid for the production of biodiesel and, consequently,

425 lowering the WWTP operation cost.

427 Acknowledgements

428 The authors wish to acknowledge the public company Gestió Ambiental i Abastament S.A.

429 (WWTP of Reus, Spain) for their kind collaboration during this project. Magdalena Olkiewicz

430 also thanks Agència de Gestió d'Ajuts Universitaris i de Recerca (AGAUR) of the Generalitat

431 of Catalunya (Spain) for the pre-doctoral scholarship. Financial support for this research was

432 provided by the Spanish Ministry of Education (Ministerio de Educación) and the FEDER

433 grant (CTM2011-23069).

\section{References}

436 [1] Willson RM, Wiesman Z, Brenner A. Analyzing alternative bio-waste feedstocks for 437 potential biodiesel production using time domain (TD)-NMR. Waste Manage $438 \quad 2010 ; 30(10): 1881-8$.

439 [2] Siddiquee MN, Rohani S. A Lipid extraction and biodiesel production from municipal $440 \quad$ sewage sludge: A review. Renew Sust Energ Rev 2011;15(2):1067-72. 
441 [3] Kwon EE, Kim S, Jeon YJ, Yi H. Biodiesel production from sewage sludge: new paradigm for mining energy from municipal hazardous material Environ Sci Technol 2012;46:10222-8.

444 [4] Zhang X, Yan S, Tyagi RD, Surampalli RY. Energy balance and greenhouse gas emissions of biodiesel production from oil derived from wastewater and wastewater sludge Renew Energ 2013;55:392-403.

447 [5] European Biodiesel Board. http://wwwebb-euorg/statsphp [cited February 2013].

448 [6] Mondala A, Liang K, Toghiani H, Hernandez R, French T. Biodiesel production by in situ transesterification of municipal primary and secondary sludge. Bioresource Technol 2009;100(3):1203-10.

451 [7] Kargbo DM. Biodiesel production from municipal sewage sludge. Energ Fuel 2010;24(5):2791-4.

453 [8] Pastore C, Lopez A, Lotito V, Mascolo G. Biodiesel from dewatered wastewater sludge: A two-step process for a more advantageous production. Chemosphere 2013;92:667-73.

[9] European Comission 2010. Environmental economic and social impacts of the use of sewage sludge on land. Service contract No 070307/2008/517358/ETU/G4.

[10] Olkiewicz M, Caporgno MP, Fortuny A, Stüber F, Fabregat A, Font J, Bengoa C. Direct liquid-liquid extraction of lipid from municipal sewage sludge for biodiesel production. Fuel Process Technol 2014;128:331-8.

[11] Dufreche S, Hernandez R, French T, Sparks D, Zappi M, Alley E. Extraction of Lipids from Municipal Wastewater Plant Microorganisms for Production of Biodiesel. J Am Oil Chem Soc 2007;84(2):181-7.

[12] Tyagi VK, Lo S-L. Sludge: A waste or renewable source for energy and resources recovery? Renew Sust Energy Rev 2013;25: 708-28.

[13] Siddiquee MN, Rohani S. Experimental analysis of lipid extraction and biodiesel production from wastewater sludge. Fuel Process Technol 2011;92(12):2241-51. 
[14] Metherel AH, Taha AY, Izadi H, Stark KD. The application of ultrasound energy to increase lipid extraction throughput of solid matrix samples (flaxseed). Prostag Leukotr Ess 2009;81(5-6):417-23.

[15] Pernet F, Tremblay R. Effect of ultrasonication and grinding on the determination of lipid class content of microalgae harvested on filters. Lipids 2003;38(11):1191-5.

[16] McNichol J, MacDougall KM, Melanson JE, McGinn PJ. Suitability of soxhlet extraction to quantify microalgal fatty acids as determined by comparison with in situ transesterification. Lipids 2012;47(2):195-207.

[17] Pilli S, Bhunia P, Yan S, LeBlanc RJ, Tyagi RD, Surampalli RY. Ultrasonic pretreatment of sludge: A review. Ultrason Sonochem 2011;18(1):1-18.

[18] Baier U, Schmidheiny P. Enhanced anaerobic degradation of mechanically disintegrated sludge. Water Sci Technol 1997;36(11):137-43.

[19] Kopp J, Müller J, Dichtl N, Schwedes J. Anaerobic digestion and dewatering characteristics of mechanically disintegrated excess sludge. Water Sci Technol 1997;36(11):129-36.

[20] Appels L, Dewil R, Baeyens J, Degrève J. Ultrasonically enhanced anaerobic digestion of waste activated sludge. Int J Sustainable Eng 2008;1(2): 94-104.

[21] Neyens E, Baeyens J, Weemaes M, De heyder B. Hot acid hydrolysis as a potential treatment of thickened sewage sludge. J Hazard Mater 2003; B98:275-93.

[22] Rice EW, Baird RB, Eaton AD, Clesceri LS. Standard methods for the examination of water and wastewater. 22nd ed. Washington: APHA AWWA WEF; 2012.

[23] Olkiewicz M, Fortuny A, Stüber F, Fabregat A, Font J, Bengoa C. Evaluation of different sludges from WWTP as a potential source for biodiesel production. Procedia Engineering $2012 ; 42: 695-706$.

[24] Jarde E, Mansuy L, Faure P. Organic markers in the lipidic fraction of sewage sludge. Water Res 2005;39(7):1215-32. 
[25] Appels L, Baeyens J, Degre`ve J, Dewil R. Principles and potential of the anaerobic digestion of waste-activated sludge. Prog Energy Combust 2008;34:755-81.

[26] Canakci M, Sanli H. Biodiesel production from various feedstocks and their effects on the fuel properties. J Ind Microbiol Biot 2008;35(5):431-41.

[27] Melero JA, Bautista LF, Iglesias J, Morales G, Sánchez-Vázquez R. Zr-SBA-15 acid catalyst: Optimization of the synthesis and reaction conditions for biodiesel production from low-grade oils and fats. Catal Today 2012;195(1):44-53.

[28] Knothe G. Dependence of biodiesel fuel properties on the structure of fatty acid alkyl esters. Fuel Process Technol 2005;86(10):1059-70.

[29] Ramos MJ, Fernández CM, Casas A, Rodríguez L, Pérez A. Influence of fatty acid composition of raw materials on biodiesel properties. Bioresource Technol 2009;100(1):261-8.

[30] Zhu F, Zhao L, Jiang H, Zhang Z, Xiong Y, Qi J, Wang J. Comparison of the Lipid Content and Biodiesel Production from Municipal Sludge Using Three Extraction Methods. Energy Fuels 2014;28:5277-83.

[31] Chang TC, You SJ, Damodar RA, Chen YY. Ultrasound pre-treatment step for performance enhancement in an aerobic sludge digestion process. J Taiwan Inst Chem E 2011;42(5):801-8.

[32] Li H, Yuan X, Zeng G, Huang D, Huang H, Tong J, You Q, Zhang J, Zhou M. The formation of bio-oil from sludge by deoxy-liquefaction in supercritical ethanol. Bioresource Technol 2010;101:2860-6.

[33] Huang H-J, Yuan X-Z, Li B-T, Xiao Y-D, Zeng G-M. Thermochemical liquefaction characteristics of sewage sludge indifferent organic solvents. J Anal Appl Pyrol 2014;109:176-84.

[34] Suzuki A, Yokoyama S-Y, Murakami M, Ogi T, Koguchi K. A new treatment of sewage sludge by direct thermochemical liquefaction. Chem Lett 1986;15(9):1425-8. 
519 [35] Itoh S, Suzuki A, Nakamura T, Yokoyama S-Y. Production of heavy oil from sewage sludge by direct thermochemical liquefaction. Desalination 1994;98:127-33.

521 


\section{$522 \quad$ Figure captions}

523 Figure 1. Comparison of sludge's fatty acids with other biodiesel feedstocks (Sludge: this

524 work; Soybean and Rapeseed: Canacki et al. (2008) [26]; Mixed fat, Waste cooking oil and 525 Crude palm oil: Melero et al. (2012) [27])

526 Figure 2. Microscopic appearance of the blended sludge floc: a) untreated sludge, b) acidified

527 sludge, c) after 10 min of ultrasonic treatment $(50 \mathrm{~W}), \mathrm{d})$ after $10 \mathrm{~min}$ of mechanical treatment $528(600 \mathrm{~W})$. 
1 Table 1. Characteristics of four types of sludge used in the present study.

\begin{tabular}{|c|c|c|c|c|}
\hline & \multicolumn{4}{|c|}{ Sludge ${ }^{(a)}$} \\
\hline & Primary & Secondary & Blended $^{(b)}$ & Stabilised \\
\hline Total solids (TS), \% & $4.2 \pm 1.2$ & $3.2 \pm 0.7$ & $3.1 \pm 0.7$ & $25.3 \pm 4.4$ \\
\hline Volatile solids (VS), \% & $3.3 \pm 0.9$ & $2.8 \pm 0.5$ & $2.5 \pm 0.6$ & $15.6 \pm 2.8$ \\
\hline Chemical oxygen demand (COD), g/L & $64.1 \pm 11.1$ & $44.1 \pm 7.5$ & $46.0 \pm 4.9$ & n.m. \\
\hline \multicolumn{5}{|c|}{ (a) Each value is the average of at least 3 samples collected on different days. } \\
\hline \multicolumn{5}{|c|}{${ }^{\text {(b) }}$ Primary and secondary at a ratio of $65: 35, \mathrm{v} / \mathrm{v}$. } \\
\hline n.m.: not measured & & & & \\
\hline
\end{tabular}


4 Table 2. Amount of lipid fraction extracted from different types of sludge by different pre-

5 treatment methods (Lipid yield (\%) on the basis of dry sludge).

\begin{tabular}{|c|c|c|c|c|c|}
\hline \multirow[b]{2}{*}{ Acidification } & \multirow[b]{2}{*}{ Pre-treatment } & \multicolumn{4}{|c|}{ Sludge ${ }^{\text {(a) }}$} \\
\hline & & Primary & Secondary & Blended $^{(b)}$ & Stabilised \\
\hline \multirow[t]{3}{*}{ Not acidified } & Untreated & $27 \pm 1$ & $9 \pm 1$ & $21 \pm 1$ & $9 \pm 1$ \\
\hline & Ultrasonic & $27 \pm 1$ & $10 \pm 1$ & $23 \pm 3$ & - \\
\hline & Mechanical & $26 \pm 1$ & $9 \pm 1$ & $22 \pm 3$ & - \\
\hline \multirow[t]{3}{*}{ Acidified } & Untreated & $25 \pm 1$ & $7 \pm 1$ & $20 \pm 1$ & $10 \pm 2$ \\
\hline & Ultrasonic & $25 \pm 1$ & $8 \pm 1$ & $22 \pm 2$ & - \\
\hline & Mechanical & $25 \pm 1$ & $8 \pm 1$ & $20 \pm 2$ & - \\
\hline
\end{tabular}

(a) Each value is the average of at least 3 samples collected on different days.

(b) Primary and secondary at a ratio of $65: 35, \mathrm{v} / \mathrm{v}$. 
7 Table 3. Transesterification yield obtained from different types of sludge by different pre-treatment methods (Saponifiable yield (\%) on the basis

8 of lipid, Biodiesel yield (\%) on the basis of dry sludge).

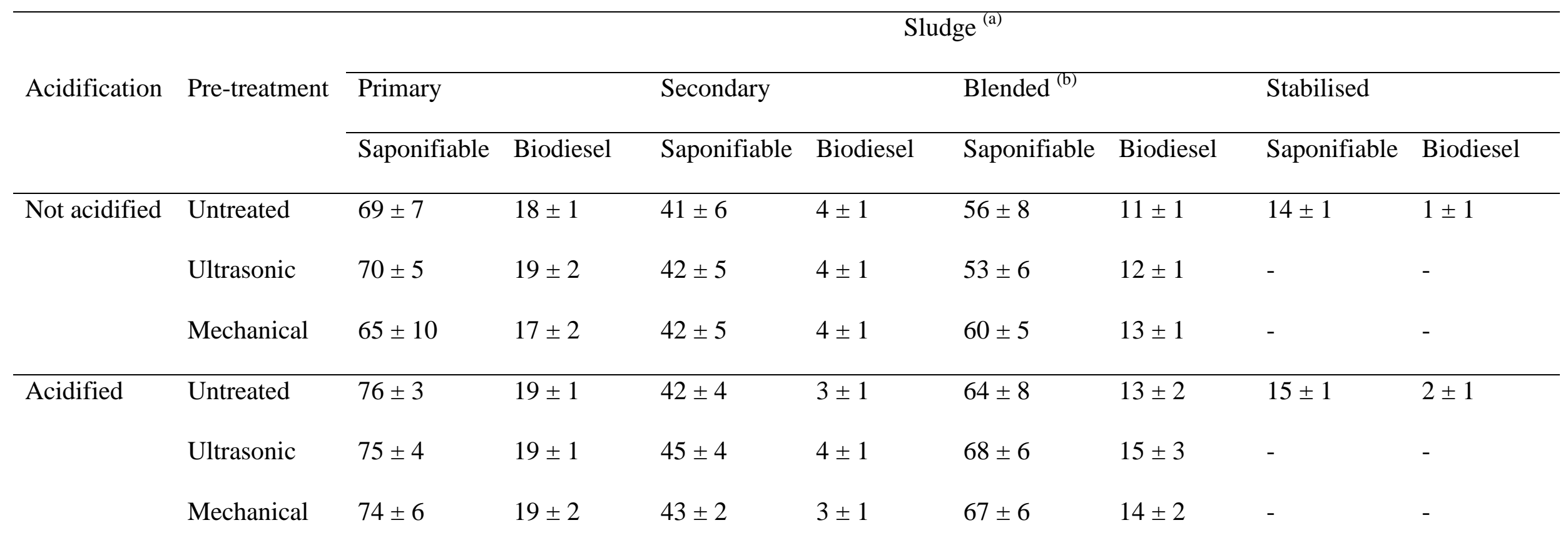

\footnotetext{
(a) Each value is the average of at least 3 samples collected on different days.
}

(b) Primary and secondary at a ratio of 65:35, v/v. 
9 Table 4a. Fatty acids composition of primary sludge for each pre-treatment (\%, w/w).

\begin{tabular}{lcccccc}
\hline & & \multicolumn{5}{c}{ Pre-treatment } \\
Fatty acid & Untreated & Ultrasonic & Mechanical & Untreated & Ultrasonic & Mechanical \\
& & & & acidified & acidified & acidified \\
\hline C12:0 & 0.3 & 0.3 & 0.3 & 0.3 & 0.3 & 0.2 \\
C14:0 & 3.0 & 3.1 & 3.0 & 3.0 & 2.8 & 2.8 \\
C15:0 & 0.2 & 0.2 & 0.2 & 0.1 & 0.1 & 0.1 \\
C16:0 & 39.0 & 39.7 & 38.8 & 43.3 & 47.0 & 44.6 \\
C16:1 & 1.1 & 0.4 & 0.4 & 0.3 & 0.2 & 0.2 \\
C:18:0 & 14.1 & 14.1 & 13.8 & 15.7 & 17.4 & 16.4 \\
C18:1 & 29.9 & 30.3 & 30.7 & 25.9 & 21.3 & 24.7 \\
C18:2 & 7.2 & 7.4 & 7.8 & 6.0 & 4.8 & 5.7 \\
Others & 5.2 & 4.5 & 5.0 & 5.4 & 6.1 & 5.3 \\
\hline
\end{tabular}

10 
11 Table 4b. Fatty acids composition of secondary sludge for each pre-treatment (\%, w/w).

\begin{tabular}{lcccccc}
\hline & & \multicolumn{5}{c}{ Pre-treatment } \\
Fatty acid & Untreated & Ultrasonic & Mechanical & Untreated & Ultrasonic & Mechanical \\
& & & & acidified & acidified & acidified \\
\hline C12:0 & 0.1 & 0.0 & 0.0 & 0.2 & 0.1 & 0.0 \\
C14:0 & 2.9 & 1.9 & 2.8 & 3.6 & 2.7 & 1.9 \\
C15:0 & 0.3 & 0.1 & 0.3 & 0.4 & 0.3 & 0.2 \\
C16:0 & 21.2 & 20.7 & 20.5 & 24.7 & 25.7 & 22.3 \\
C16:1 & 11.6 & 11.3 & 11.8 & 10.2 & 10.7 & 10.8 \\
C:18:0 & 9.5 & 9.9 & 9.1 & 10.4 & 10.1 & 8.7 \\
C18:1 & 29.5 & 30.6 & 29.0 & 26.0 & 26.0 & 28.8 \\
C18:2 & 8 & 8.6 & 7.3 & 7.7 & 6.9 & 6.5 \\
Others & 16.9 & 16.9 & 19.2 & 16.8 & 17.5 & 20.8 \\
\hline
\end{tabular}

12 
13 Table 4c. Fatty acids composition of blended sludge for each pre-treatment $(\%, w / w)$.

\section{Pre-treatment}

\begin{tabular}{|c|c|c|c|c|c|c|}
\hline Fatty acid & Untreated & Ultrasonic & Mechanical & $\begin{array}{l}\text { Untreated } \\
\text { acidified }\end{array}$ & $\begin{array}{l}\text { Ultrasonic } \\
\text { acidified }\end{array}$ & $\begin{array}{c}\text { Mechanical } \\
\text { acidified }\end{array}$ \\
\hline C12:0 & 0.3 & 0.2 & 0.4 & 0.3 & 0.2 & 0.2 \\
\hline C14:0 & 3.2 & 3.3 & 3.4 & 2.8 & 3.0 & 3.0 \\
\hline C15:0 & 0.3 & 0.2 & 0.3 & 0.2 & 0.1 & 0.1 \\
\hline C16:0 & 40.7 & 40.6 & 41.1 & 38.7 & 38.8 & 37.9 \\
\hline C16:1 & 2.0 & 2.1 & 1.6 & 1.8 & 1.5 & 1.4 \\
\hline C:18:0 & 13.3 & 12.8 & 13.7 & 14.3 & 14.5 & 14.1 \\
\hline C18:1 & 24.6 & 26.1 & 24.4 & 27.1 & 26.4 & 28 \\
\hline C18:2 & 5.2 & 4.8 & 4.6 & 5.1 & 5.1 & 5.3 \\
\hline Others & 10.4 & 9.9 & 10.5 & 9.7 & 10.4 & 10.0 \\
\hline
\end{tabular}

14 
15 Table 4d. Fatty acids composition of stabilised sludge (\%, w/w).

\begin{tabular}{lcc}
\hline & \multicolumn{2}{c}{ Pre-treatment } \\
\cline { 2 - 3 } Fatty acid & Untreated & Untreated acidified \\
\hline C12:0 & 0.0 & 0.0 \\
C14:0 & 0.0 & 0.0 \\
C15:0 & 0.0 & 0.0 \\
C16:0 & 30.8 & 33.8 \\
C16:1 & 2.5 & 2.1 \\
C:18:0 & 10.3 & 10.7 \\
C18:1 & 36.2 & 35.1 \\
C18:2 & 9.5 & 8.8 \\
Others & 10.7 & 9.5 \\
\hline
\end{tabular}

16

17

18

19 
Figure 1

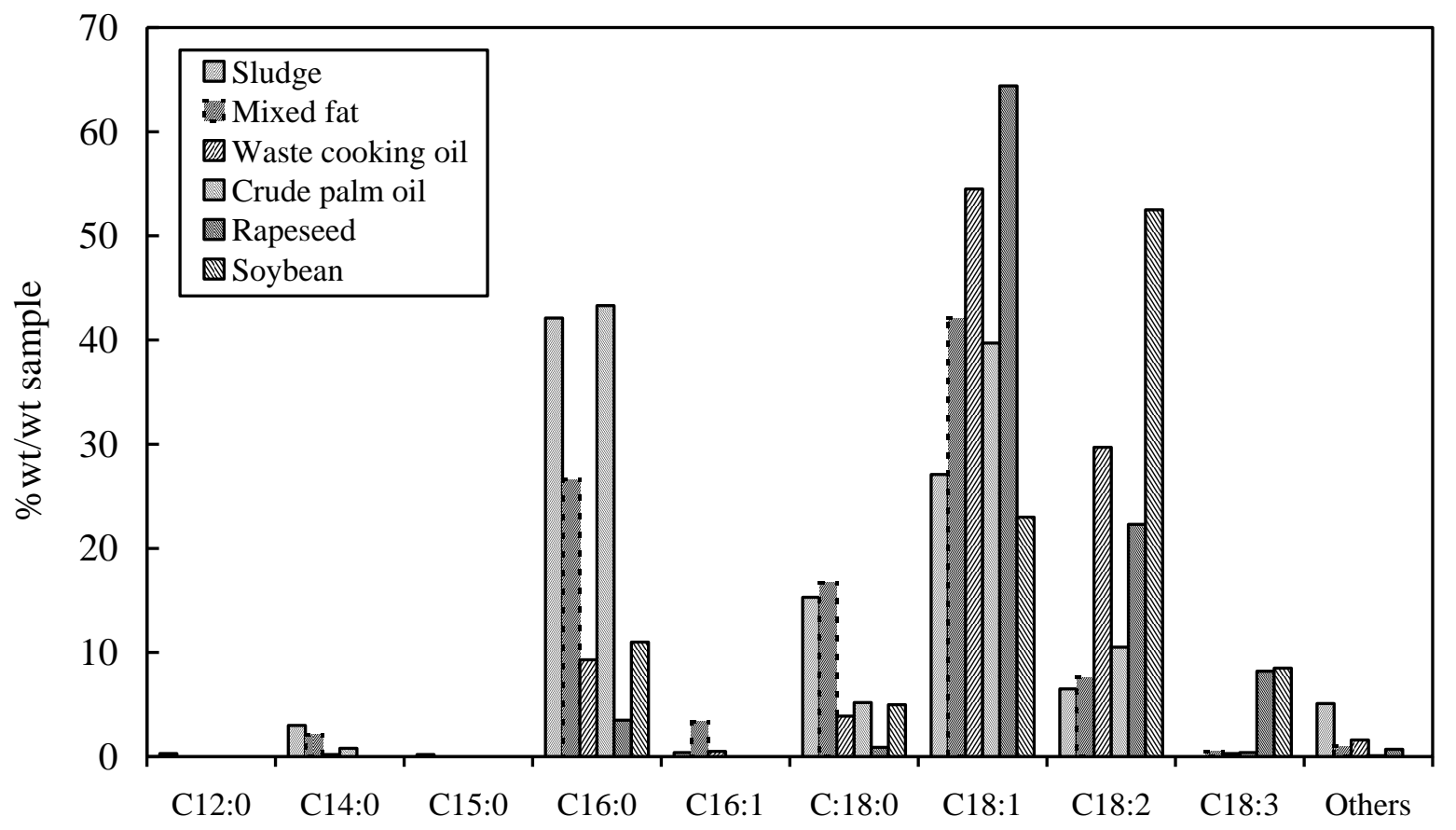

Fatty acid 

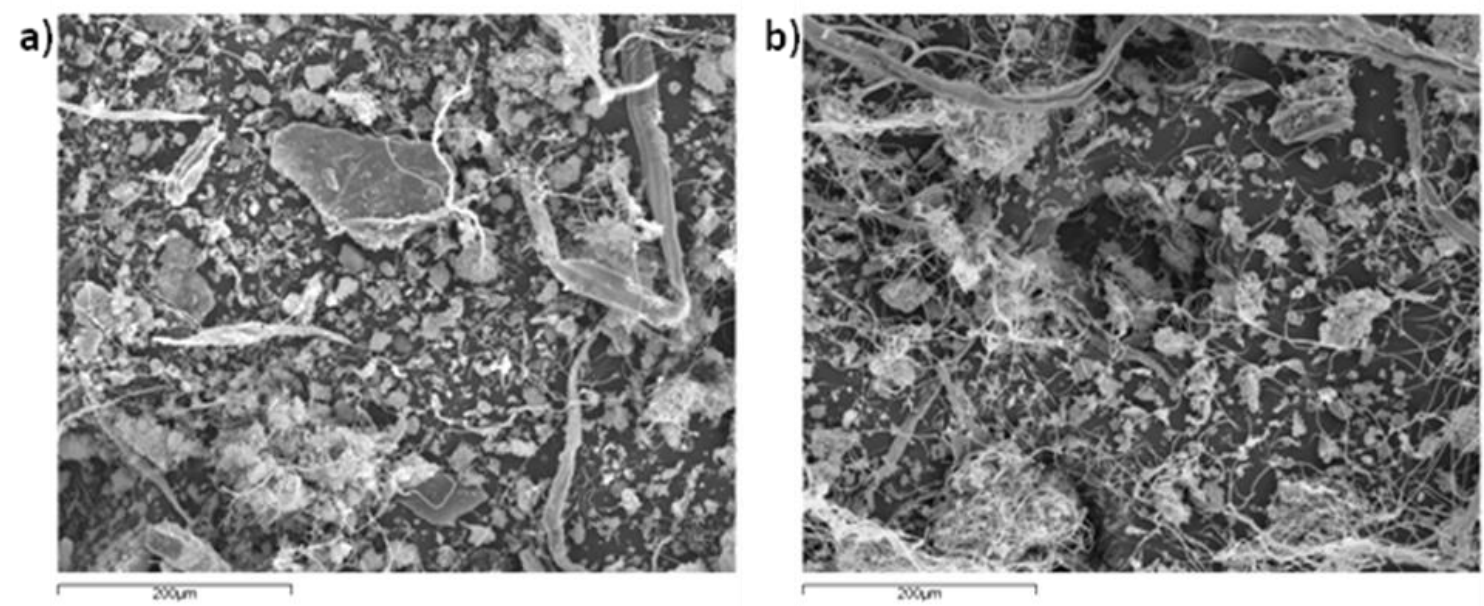

c)

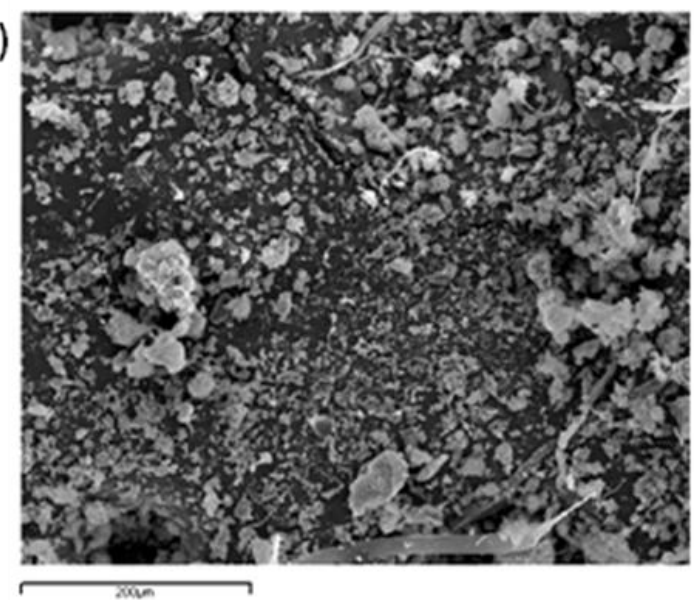

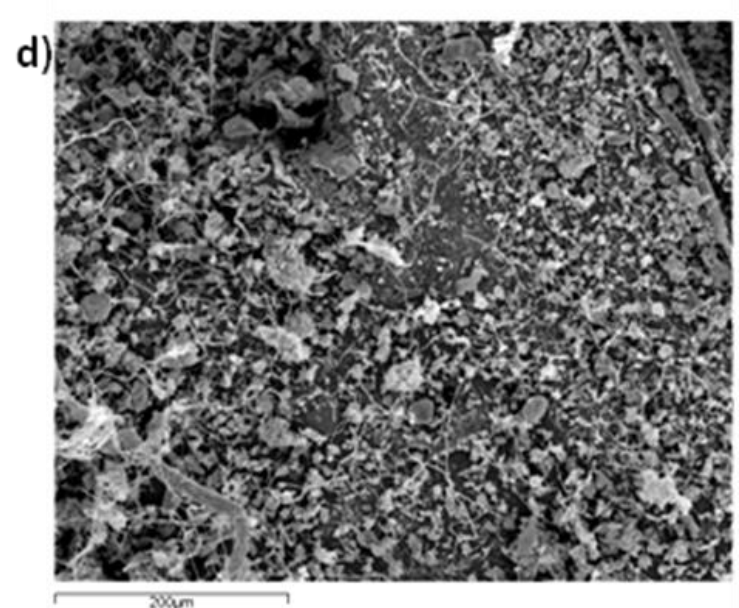

